REVISTA DO CENTRO DE CIÊNCIAS DA EDUCAÇÃO

Volume 36, n. 4 - p. 1398-1418, out./dez. 2018 - Florianópolis

Rafael Caetano do Nascimento

Universidade Estadual Paulista,

UNESP, campus de Rio Claro

Email: racanascimento@gmail.com

(D) http://orcid.org/0000-0002-2248-9092

Maria Rosa Rodrigues Martins de Camargo

Universidade Estadual Paulista,

UNESP, campus de Rio Claro

Email: mrosamc@rc.unesp.br

(i) http://orcid.org/0000-0003-0490-7227

Recebido em: 31/08/2017

Aprovado em: 13/06/2018

\section{Escrita na prisão: linhas de invenção e resistência}

\section{Rafael Caetano do Nascimento Maria Rosa Rodrigues Martins de Camargo}

\section{Resumo}

O objetivo deste artigo foi apresentar algumas reflexões e discussões a respeito da potencialidade da prática da escrita em um contexto de privação de liberdade a partir de uma oficina educativa realizada no Centro de Ressocialização Masculino (CR) de Rio Claro. A pergunta que orientou o estudo foi: o que movimenta e o que pode a escrita na prisão? Para isso, trouxe a narração de minha trajetória como professor de Ciências da Natureza neste espaço como forma de trazer contribuições para se pensar a disciplina, a punição e o cotidiano nos espaços prisionais. Foi realizada uma contextualização do sistema prisional como local de aprisionamento da pobreza, da disciplina ostensiva e reformativa sobre o indivíduo e o lugar que o CR ocupa nesse sistema prisional. Com relação à metodologia, para uma perspectiva da escrita, há contribuições teóricas na linha de autores como Deleuze e Foucault. Criar narrativas para o que observei ao atravessar um contexto prisional, tanto como professor quanto como pesquisador, aproxima-me do método cartográfico, o qual abriu possibilidades para se pensar a relação da prática da escrita com os processos de invenções de si e resistência ao poder disciplinar em espaços de encarceramento.

Palavras-chave: Prisão. Escrita. Resistência. 


\begin{abstract}
Writing in prision: lines of invention and resistance

The purpose of this article was to present some reflections and discussions about the potential of the practice of writing in a context of deprivation of liberty from an educational workshop held at the Centro de Ressocialização Masculino (CR) in Rio Claro. The question that guided the study was: what moves and what can writing in prison? For this, I brought the narration of my trajectory as a professor of Natural Sciences in this space as a way to bring contributions to think about discipline, punishment and daily life in prisons. A contextualization of the prison system was carried out as a place of imprisonment of poverty, ostensive and reformative discipline over the individual and the place that the CR occupies in this prison system. With regard to methodology, for a perspective of writing, there are theoretical contributions in the line of authors as Deleuze and Foucault. Creating narratives for what I observed when crossing a prison context, both as a teacher and as a researcher, brings me closer to the cartographic method, which opened up

Keywords:

Prison. Writing. Resistance.

possibilities for thinking about the relation between the practice of writing and the processes of self-invention and resistance to power discipline in incarcerated spaces.
\end{abstract}

\section{Resumen}

Palabras claves:

Prisión. Escritura. Resistencia.

\section{Escritura en la cárcel: líneas de invención y resistencia}

El objetivo de este artículo fue presentar algunas reflexiones y discusiones acerca de la potencialidad de la práctica de la escritura en un contexto de privación de libertad a partir de un taller educativo realizado en el Centro de Ressocialización Masculino (CR) de Río Claro. La pregunta que orientó el estudio fue: ¿qué mueve y qué puede la escritura en la prisión? Para eso, trajo la narración de mi trayectoria como profesor de Ciencias de la Naturaleza en este espacio como forma de traer contribuciones para pensar la disciplina, el castigo y el cotidiano en los espacios prisionales. Se realizó una contextualización del sistema penitenciario como lugar de encarcelamiento de la pobreza, de la disciplina ostensiva y reformativa sobre el individuo y el lugar que el CR ocupa en ese sistema penitenciario. Con respecto a la metodología, para una perspectiva de la escritura, hay contribuciones teóricas en la línea de autores como Deleuze y Foucault. Crear narrativas para lo que observé al atravesar un contexto prisional, tanto como profesor como investigador, me aproxima del método cartográfico, el cual abrió posibilidades para pensar la relación de la práctica de la escritura con los procesos de invenciones de sí y resistencia al poder disciplinario en espacios de encarcelamiento. 


\section{Introdução}

Por onde se tecem as linhas vivas que dão formas e sentidos às palavras no compor de uma escrita? O sujeito que escreve, talvez, vá pelo meio: travessia entre saberes e poderes que o desafiam. Exercício fronteiriço, lançar-se na escritura é lugar de produzir consigo aquilo que ainda não se é. Mistérios do outro de si que virão, processo devir-alguma-coisa. Antes de se pensar estas questões, escrever é uma tarefa artesanal: trata-se de colocar uma letra, depois outra e outra; ato de composição que, muitas vezes, carrega a força da linguagem para enfrentar tensões do presente.

Iniciar o texto com estes dizeres a respeito da prática da escrita abre o objetivo deste artigo, que é a discussão de duas questões: (1) os desdobramentos de uma atividade educativa dentro de uma prisão, tendo a escrita como mote de seu acontecimento; (2) as relações do sujeito com a prática da escrita no ambiente prisional. Elas são frutos da pesquisa de mestrado em educação desenvolvida pelo presente autor entre os anos de 2015 e 2017 e intitulada "Silenciosos gritos por entre as grades e as ruas: escrita e invenções de si no Centro de Ressocialização Masculino de Rio Claro". Fomentar reflexões acerca das múltiplas relações do sujeito com a prática da escrita faz parte dos temas investigados e experimentados pelo grupo de estudos Escriarte, sob coordenação da Prof ${ }^{a}$. Dr ${ }^{a}$. Maria Rosa Rodrigues Martins de Camargo, docente do Departamento de Educação da UNESP - Rio Claro.

A atividade educativa foi desenvolvida no Centro de Ressocialização Masculino "Luiz Gonzaga da Arruda Campos" e aconteceu em oito encontros com reeducandos dessa unidade, no período de outubro a dezembro de 2016. Almejava ser um momento e lugar de encontro para a experimentação de palavras, escritas e sentidos, composições de linguagens; espaço para a produção de narrativas de si e do outro. Sua dinâmica propunha a elaboração de textos a partir de dispositivos que provocassem o compartilhar de leituras de mundo. Para se pensar o que vem a ser os dispositivos, Foucault (2013, p.364) explica:

Por esse termo tento demarcar, em primeiro lugar, um conjunto decididamente heterogêneo que engloba discursos, instituições, organizações arquitetônicas, decisões, regulamentares, leis, medidas administrativas, enunciados científicos, proposições filosóficas, morais, filantrópicas. Em suma, o dito e o não dito são os elementos do dispositivo. O dispositivo é a rede que se pode estabelecer entre esses elementos.

Com o nome de Travessias da vida: oficina de invenções do cotidiano, os encontros não pretendiam produções em determinados gêneros literários, mas colocar em jogo formas de atenção para as maneiras como nomeamos o sentido e o não-sentido daquilo que nos atravessa, que nos dá forma e nos encaminha ao imprevisível (LARROSA, 2002). 
A oficina buscou, escutou e se pôs a pensar a escrita como possibilidade expansiva da subjetividade em uma atmosfera de controle, privação e isolamento, que caracteriza a instituição prisional. O espaço ali formado adquiriu, com o decorrer dos encontros, um lugar onde as pessoas que vivem em condição de privação de sua liberdade pudessem exercer o direito à liberdade de expressão e à educação, direitos estes fundamentais e garantidos pela constituição. São lugares que permitem a construção de outras narrativas de si e do outro, que contrastam e contrapõem à imagem estereotipada e preconceituosa do presidiário e delinquente, recebidos na condenação pelo sistema de justiça. É um espaço para se acrescentar linhas resistentes na malha do discurso.

Para problematizar tais questões, conto momentos de minha trajetória como professor de Ciências da Natureza em duas unidades prisionais de Rio Claro: o Centro de Ressocialização Masculino (CRM) e o Centro de Ressocialização Feminino (CRF). Esse recurso me parece profícuo por permitir articulações entre os componentes das diversas esferas da vida ao invés de separá-los (RAITZ; CHIARELOTTO, 2005), visto que permite articular e colocar, em jogo, componentes micro e macroestruturais, além de me aproximar do processo de uma possível escrita autobiográfica, como propõe Rolnik (2007, p.22): "Podese dizer que o texto é autobiográfico, desde que entendamos por 'auto', aqui, não a individualidade de uma existência, mas a singularidade do modo como atravessam seu corpo as forças de um determinado contexto histórico". Assim, a experiência de narrar minha prática educativa me torna sujeito da prática da escrita, objeto do presente estudo.

Seguir por este caminho me aproxima, também, da perspectiva teórico-metodológica cartográfica, a qual orientou a pesquisa. Ela é um conceito desenvolvido por Deleuze e Guattari e pode ser utilizada em pesquisas de campo voltadas para o estudo das subjetividades (KASTRUP, 2007). Para que a cartografia possa existir, há o trabalho do cartógrafo que, em pesquisas na área da educação, pauta-se em estar atento às potências de uma vida, por onde e como ela se faz, se desfaz e se refaz nos espaços educacionais (OLIVEIRA; PARAÍSO, 2012). Esta potência, que carrega um desejo de viver, arranja-se nos encontros, nas narrações, nas produções de sentido, na e pela escrita. Como explica Oliveira e Paraíso (2012), a cartografia é um trabalho sobre as linhas: linhas que definem, significam, territorializam e constroem uma rota segura em um espaço, ou linhas que desterritorializam, que fogem e escapam; linhas que articulam sensações, pensamentos e comunidade, articulações que podem aparecer nos movimentos do escrever.

Alguns momentos dos encontros serão movimentados e articulados nessa escrita, no intuito de ser e de se fazer uma discussão da inventividade e potencialidade da escrita nos desafios de se viver aprisionado. Com relação a alguns problemas do sistema prisional, recorro às contribuições dos escritos de autores como Baratta (2004a; 2004b), Bauman (2000), Foucault (2002; 2013) e Wacquant (2011). No 
que tange aos processos de produção de subjetividades, de singularização e invenção de si, apoio-me nos estudos sobre a linguagem de Foucault (1992; 2002; 2013), Deleuze (2013; 1988/89) e Guattari (2012).

\section{Prisões: Centro de Ressocialização e o projeto de reforma}

Além desse portão, havia o mundo luminoso da liberdade. E, de dentro, aquele mundo nos parecia como um conto de fadas, como uma miragem. O nosso mundo nada tinha de análogo com esse outro! Eram leis, costumes, hábitos característicos, uma casa mortaviva, uma vida à parte, de homens à parte. (DOSTOIEVSKI, 1953, p.38)

As prisões que adentrei funcionam a partir do modelo prisional chamado Centro de Ressocialização (CR), o qual está inserido em um contexto prisional maior, de modo que este modelo tem determinadas características que o difere de outros, como, por exemplo, o das convencionais penitenciárias, as quais são mais conhecidas pelas más condições em que recebem e tratam seus internos do que pelo desempenho efetivo que lhes são esperado (BAUMAN, 1999; COSTA, 2006; MONTEIRO; CARDOSO, 2013). É justamente pelo quadro crítico de violação dos dieitos humanos nas prisões brasileiras que surge o CR, trazendo uma proposta de humanização das penas privativas de liberdade e, assim, buscando enfrentar os altos índices de reincidência criminal (FAUSTINO; PIRES, 2007).

A história do CR remete ao ano 2000, quando Nagashi Furukawa assume a cadeira de Secretário de Administração Penitenciária do estado de São Paulo. Uma de suas propostas foi a implantação do Programa Cidadania no Cárcere, o qual "acredita na efetividade da ressocialização dos presos por meio da transformação da realidade carcerária embasada na integração das ações do Estado, da sociedade, da iniciativa privada e fundamentalmente dos familiares do preso" (BUENO, 2005, p.51). A humanização da pena é o objetivo deste programa, reconhecendo que "não é possível conseguir a regeneração do homem encarcerado sem o atendimento mínimo de seus direitos naturais” (BUENO, 2005, p.51). Os CRs são, então, efetivamente criados como uma política pública criminal do estado de São Paulo em função da implementação deste programa. Como política pública criminal, Costa (2006, p.68) entende que seja:

[...] o conjunto de procedimentos repressivos por meio dos quais o Estado reage contra o crime. As diretrizes de uma política criminal e penitenciária enunciam uma série de princípios básicos e propósitos a serem perseguidos, objetivando o aprimoramento da reação ao fenômeno crime, bem como da execução penal do país em consonância com a Constituição Federal, a legislação pertinente e o programa nacional de direitos humanos, tudo isto em harmonia com as regras mínimas estabelecidas pela ONU, para o tratamento do preso, além das regras de Tóquio e as do Conselho Nacional de Política Criminal Penitenciária.

Inicialmente, todo CR teria a gestão compartilhada entre Estado e ONG, sendo responsabilidade desta proporcionar aos reeducandos toda forma de assistência social e àquele caberia administrar a segurança e a disciplina na unidade (COSTA, 2006; VEDOVELLO, 2008). Este modo de gerir traz 
discussões a respeito de suas vantagens e desvantagens, sendo que, dentre as desvantagens, há a incerteza da continuidade dos serviços caso os convênios entre Estado-ONG não fossem mais firmados.

Em 2012, quando os CRs deixaram de ser administrados em parceria com as ONGs para ser de total responsabilidade do Estado. Campos (2015) comenta que o fim desse vínculo se deve ao fato de que a parceria era inexistente na maioria das unidades e, ao invés de buscarem meios para se firmarem, optaram por encerrar as atividades conjuntas. A qualidade e a oferta dos serviços de assistência ao preso não continuaram as mesmas, mas, apesar disso, os CRs continuam sendo um espaço diferente das penitenciárias e alguns direitos estão garantidos no cumprimento da pena.

Quanto a sua estrutura física, os CRs estão projetados para comportar 210 pessoas e este limite é respeitado, não ocasionando a superlotação dos alojamentos e permitindo um atendimento mais individualizado e humanizado. Algumas características pertinentes das mudanças arquiteturais desta instituição são: muralhas substituídas por muros de 3 metros de altura, não existindo mais a vigilância da Polícia Militar; no lugar das celas, alojamentos; banheiros coletivos e com chuveiros quentes; salas para atendimento social, psicológico e pedagógico; oficinas de trabalho, áreas para visitas familiares, barbearia, cultos religiosos, cozinha industrial, refeitório e lavanderia; armazém para o atendimento de necessidades pessoais, de higiene e de alimentação (COSTA, 2006; FAUSTINO, 2008).

Quanto ao sistema prisional, os CRs configuram-se como prisões de pequeno porte, destinados a presos que se encontram no regime fechado, semiaberto e provisório, contudo, é necessário passar por uma triagem realizada por uma equipe técnica, que busca selecionar um perfil ideal: "presos de ação criminosa de baixa periculosidade, com tendência à baixa agressividade, com delinquência ocasional e/ou criminalidade acidental, considerados crimes situacionais, e os de primariedade prisional” (FAUSTINO, 2008, p.84). Há, neste perfil, a ideia de presos com potencial de reabilitação, o qual leva em consideração o interesse do reeducando em ir para o CR, suas condições familiares, o uso de drogas, a periculosidade do delito cometido, sua reincidência nos crimes e se pertence a alguma facção criminosa (VEDOVELLO, 2008, p.79). Com parecer favorável, o reeducando é transferido para o CR e passa por um período de observação e adaptação. Caso apresente problemas de convívio ou qualquer outro comportamento considerado indisciplinar de acordo com as regras da instituição, ele é transferido novamente para a Penitenciária, ficando impedido de retornar a algum CR. Esta medida é considerada uma segunda punição aos detentos, além de servir como exemplo e ameaça aos demais internos da unidade.

A existência de um processo de triagem e da punição com transferência para penitenciária em função da manutenção da disciplina e da ordem, dentro de um sistema que pretende ser inovador na gestão prisional e nos métodos de se alcançar um efetivo processo ressocializador, mostra que este projeto 
não foi criado para determinados tipos de preso. Para estes que não se encaixam no perfil do CR, que são sabidamente violentos ou instáveis, corrobora-se as perguntas feitas por Campos (2015, p.79): "Esses sujeitos não cabem no processo (re) socializador? Não há (re) socialização voltada para eles?”. Apesar de não ser o intuito deste estudo respondê-las, elas devem ser pronunciadas por reportarem a problemáticas que são persistentemente vividas no sistema prisional e com necessidade de ainda serem superadas.

Quanto ao cotidiano prisional, todos os presos da unidade são obrigados a trabalhar e, quem não terminou os estudos, a estudar. São deveres básicos a serem cumpridos para a permanência na unidade e que garantem a remissão de pena, os quais levam a uma rotina extremamente rígida e repetitiva, tensa e fortemente demarcada pelo trabalho e pela escola. Dessa forma, todos os presos possuem funções, ocupam postos de trabalho e há horários para cada mudança de atividade. Costa (2006) lembra que os CRs, apesar de garantirem melhores condições materiais à pessoa presa, não deixam de ser prisão e, portanto, fazem prevalecer o controle do Estado para a garantia da disciplina e para impedir a aleatoriedade de movimentação dos indivíduos, isto é, dominação e controle dos corpos.

Com o controle quase total das atividades dos indivíduos e das situações cotidianas, os CRs reproduzem as práticas dos modelos convencionais de prisão, uma contradição com seu discurso de inovação da gestão penal. Além disso, a maioria das punições aplicadas nos CRs é a transferência dos indivíduos para as penitenciárias, a qual é realizada sem a devida investigação e análise da falta cometida, violando, assim, o direito de defesa do preso. Ao ser transferido, a unidade não pode mais trabalhar com o sujeito. Para onde vai o discurso ressocializador quando, no momento da falta, as necessidades mais subjetivas do indivíduo são ignoradas? Sem a garantia de uma efetiva reintegração harmônica do reeducando à sociedade, resta, na maioria das vezes, o interesse do Estado em controlá-lo (COSTA, 2006).

Quando se olha para as instâncias de poderes e saberes que se cruzam na vida do aprisionado, Tejerina (2016, p.26) aponta que o sujeito preso está na intersecção de três conjuntos institucionais: o poder judicial, o serviço penitenciário e o sistema educativo; ele é visto, portanto, como um sujeito do tratamento criminológico, um sujeito judicializado e um sujeito da ação educativa. Majoritariamente, elas operam a partir do discurso de reforma moral do indivíduo e sua reeducação para a posterior ressocialização. É a política dos REs.

Portanto é sob o discurso de agir sobre o indivíduo e reformá-lo que as prisões se erguem, mas, ao invés disso, produzem e perpetuam a criminalidade necessária para o funcionamento dos atuais mecanismos de controle político. Diante disso, para compreender por que se continua a apostar em prisões como solução da violência, é necessário articular essa pergunta com outras duas: para quem a 
prisão é um inconveniente? Para quem o sistema carcerário está falido? Ela não é um inconveniente para quem se alimenta do medo veiculado na sociedade. A violência produzida pelas prisões é lucrativa. Há um círculo que necessita ser quebrado: a prisão produz aquilo que ela deve, supostamente, combater: a delinquência (FOUCAULT, 2013). Segundo Baratta (2004a), esta contradição operante no sistema penal não é uma obra do acaso, senão que a própria condição de funcionamento desse sistema.

A criminalidade é produzida ou reforçada cada vez que uma pessoa, ao passar pelo sistema penal, recebe a identidade de delinquente. Sabe-se que a maioria da população presa é proveniente de um grupo social já marginalizado de seus direitos e, nesse contexto, a prisão é um processo secundário de marginalização (BARATTA, 2004b). Que vida lhes aguarda se o sistema prisional não promove possibilidades para que saiam desses processos? Historicamente é esse sistema penal que recruta e produz um grupo de delinquentes ao marcar indivíduos já marginalizados com o estereótipo do criminoso: “[...] a prisão foi o grande instrumento de recrutamento. A partir do momento que alguém entrava na prisão se acionava um mecanismo que o tornava infame, e quando saía, não podia fazer nada senão voltar a ser delinquente" (FOUCAULT, 2013, p.76).

A pobreza, a periferia, o marginal tornam-se alvos desse sistema; não distante, são eles a maior parte da população carcerária brasileira (IRELAND, 2011). Para Wacquant (2011), atualmente, as prisões seguem uma política de aprisionamento massivo da pobreza. Segundo o autor (2011), o avanço do neoliberalismo enxugou o Estado social e, no lado oposto ao Estado mínimo, organizou um imenso Estado penal, no qual surgem políticas públicas de segurança que reforçam o encarceramento massivo da pobreza e de todo o maquinário de produção da delinquência.

Wacquant (2011) argumenta que as prisões atuais são erguidas para aprisionar a miséria e varrê-la do campo visual, exercendo um higienismo social. O fato de uma classe social pobre ocupar majoritariamente os presídios brasileiros não é, portanto, fruto do acaso ou, então, o reflexo de uma tendência genética/biológica das pessoas que acabam praticando atos ilícitos. A criminalidade é uma realidade que se aproxima muito mais de uma produção política que reflete históricas desigualdades reproduzidas no encadeamento das ações humanas do que um problema a ser resolvido na correção punitiva de determinados indivíduos.

Os presídios brasileiros estão cercados pela injustiça e pela violência. Injustiça de um poder que, antes de garantir aos sujeitos seus direitos, pune-os pelas consequências de sua ausência. Violência de um poder que se mantém operante a partir da exclusão desses sujeitos. Privando-os da liberdade, constrói-se a imagem da segurança pública e da punição à violência: saciam-se os medos da sociedade com relação a ela mesma. Ao mesmo tempo, alimenta-se a obsessão pela punição do crime/criminoso gerando uma 
histeria da população, que grita por proteção. E "Cada vez que um delinquente cai varado de balas, a sociedade sente um alívio na doença que a atormenta” (GALEANO, 2013, p.81).

Habitar as prisões é viver por entre regras institucionais que tencionam as relações cotidianas e envolvem perspectivas de modos de ser. Na vida social da prisão, há um constante jogo consigo mesmo. Para observar por onde este jogo se faz, olhamos para o CR masculino, a prisão vista de dentro.

\section{A prisão vista de dentro:}

Pode-se ler, ver filmes, informar-se sobre, escutar histórias, conhecer alguém que já esteve preso, mas adentrar a prisão e vivenciar seu cotidiano um pouco mais de perto é outra coisa. E, sob a ótica da experiência, cada prisão é única para aquele que a vive, seja como preso, agente penitenciário, familiar, diretor, professor, palestrante ou qualquer identidade que se vista ao conhecê-la. Da experiência, produzimos palavras e, nas palavras, nos encontramos na e para a partilha dos sentidos.

Eu nunca havia adentrado uma unidade prisional até o dia em que fui ao CR masculino de Rio Claro divulgar e convidar os reeducandos a participar de um projeto de leitura que Felipe ${ }^{1}$ e eu almejávamos desenvolver. Devido ao regimento da unidade, fomos autorizados a entrar no período noturno, momento destinado à educação escolar. Na unidade não há salas de aula fixas; o espaço de convivência é reorganizado todos os dias para que as aulas aconteçam e, por volta das dez da noite, há o desmonte da escola para que as atividades do dia seguinte possam ocorrer conforme as normas da casa. Curiosamente, monta-se e desmonta-se a escola todos os dias, exceto nos finais de semana.

As boas condições do lugar chamavam a atenção: canteiros de plantas bem cuidados, um belo jardim dentro da unidade, em torno do qual fica a sala dos professores e professoras, assim como a sala do diretor, da enfermaria, do almoxarifado, da assistência social e da ONG. Tudo estava limpo e bem iluminado; a cor amarela das paredes destoava dos acinzentados presídios da televisão; nada da insalubridade e precariedade tão comuns dos noticiários. Ao mesmo tempo, outras características me causavam vertigem: do lado de fora, o portão azul imenso e completamente fechado, e o qual dá acesso aos interiores do CR; do lado de dentro, as grades-enormes-azuis, o barulho metálico ao abri-las e fechálas, as chaves enormes que impedem ou permitem passagens, a mistura de cheiros de diversos lugares: cozinha, lavanderia, produtos de limpeza e dos perfumes do banho recém tomado pelos reeducandos.

Acompanhava Felipe e Aline. Segui-os até a primeira sala de aula onde faríamos a divulgação. Era o ano de 2012 e, nesta época, algumas salas eram montadas nas oficinas de trabalho. Quando entrei,

\footnotetext{
${ }^{1}$ Amigo dos caminhos da educação desde 2010, quando integrávamos o Projeto de Educação de Jovens e Adultos (PEJA) da UNESP - Rio Claro. Juntos desenvolvemos, em 2012, o projeto de leitura LerTeatro no CR masculino de Rio Claro.
} 
cabeças raspadas, camisetas brancas e calças amarelas ou beges ${ }^{2}$. Foi impossível não reparar; todos me pareciam muito iguais. Sentados, olhavam-me e aguardavam a fala. Eu, um tanto desconcertado, estava incomodado com os olhares. Percebi que não fazia ideia do que era estar preso e, menos ainda, de como chegaram até ali. Disse meu nome e fiquei quieto. A divulgação ficou por conta de Felipe.

A cena marcou minha primeira entrada na prisão e aquela forçada igualdade com pessoas tão diferentes me estranhou. O borrão branco e amarelo que eu via, dizia algo, acentuava tom e lugar das coisas: quem são os criminosos. Em um primeiro momento, essa igualdade funcionava para apagar singularidades, anular histórias de vida e colocar todos na mesma esteira de produção de sujeitos. Sentese, rapidamente, a condenação que recebem no tribunal. Considerados os culpados pelos males sociais, são-lhes destinadas a punição e a necessidade da reforma.

Em meados de setembro de 2012, após a divulgação do projeto, iniciava-se a primeira roda de leitura. Nesses encontros tive o primeiro contato com algumas pessoas que viviam no CR. Entre as leituras de uma adaptação do livro de Dom Quixote, contavam também sobre suas vidas: relações familiares, amizades, preconceitos com a periferia, violência policial, abandono escolar, envolvimento com o uso e a venda de drogas, trabalho e seus sonhos. Conhecer e escutar essas histórias vai na contramão da condenação, pois após o martelo do juiz, o prisioneiro passa a ser visto e observado quase que somente pelo viés do crime, tendo suas outras identidades apagadas. Ali eram pais, filhos, irmãos, avós, estudantes, artistas e trabalhadores. Por isso suas histórias são tão importantes: para que o humano, ali existente, resista.

No ano seguinte, em 2013, eu estava como professor de Ciências da Natureza no CR masculino e comecei a vivenciar mais de perto aquele cotidiano prisional. Ali existe um horário para tudo: tomar banho, montar a escola, chegada dos alunos para a aula (18h15min), tomar o remédio contra dor, desmontar a escola, guardas as cadeiras, varrer o chão, apito e ir para cama. No controle do espaçotempo, negociar a ida ao banheiro, a busca dos óculos esquecidos ou qualquer outra possibilidade de quebra da mesmice, é conseguir dar um passo fora do ritmo.

Sobre a força do tempo, também aprendi com um aluno enquanto desmontavam a escola. Ele dizia: "Aqui é como se você tivesse uns obstáculos e precisasse desviar deles a todo momento. É um estado de alerta constante. Estressa demais, você chapa ${ }^{3}$, fica louco, com raiva. E não tem com quem falar, eu converso com minha mãe no fim de semana e só”. Perguntei logo em seguida: “E qual é o maior

\footnotetext{
${ }^{2}$ A cor da calça sinaliza o tipo de regime em que o indivíduo se encontra: fechado, bege e semiaberto, amarela.

${ }^{3}$ A expressão chapa é uma gíria utilizada para dizer de um estado que o indivíduo se encontra com seus pensamentos e sentimentos dentro da prisão.
} 
obstáculo aqui?". Ele respirou e disse buscando as palavras: “É, na física, sabe a força peso? É a força peso do tempo. Isso é o mais difícil pra mim... a força peso do tempo".

Em 2015, eu ainda era professor na unidade e uma vez por mês fazíamos o Cinedebate na escola, onde assistíamos algum filme e, em seguida, realizávamos uma discussão juntamente com todos os alunos. Enquanto assistíamos ao filme $\mathrm{Amistad}^{4}$, dois desistiram de ver e não foram para o alojamento, pois se o fizessem, ficariam com falta e sob o risco de serem transferidos para a penitenciária. Foram para o banco próximo à grade que dá acesso ao pátio interno, que só se abre para as visitas dos finais de semana. Outros dois seguiram o movimento. De longe, do outro lado da área de convivência - onde era realizado o Cinedebate - eu os observava. Corpos e olhares pesados, envoltos por um tempo imóvel. Um deles permanecia com as costas apoiadas na parede e as pernas estiradas no chão; outro, com um pé apoiado na grade, mirava o céu noturno. No chão, outro apoiava os cotovelos nas coxas e segurava com as mãos a cabeça tombada. Outro me aparecia pela metade, apenas as pernas estiradas no chão. Ali, juntos, entregues, esperando, esperando, esperando... parados, estáticos. E o pensamento... Sabe-se lá por onde anda. Lembrei-me de uma expressão que sempre me diziam "É que no mundão, o tempo não para".

O corpo é o alvo do controle. Controla-se o tempo para controlar o corpo. Aí reside a técnica de produzir a reforma do sujeito aprisionado (FOUCAULT, 2002). Nesse universo, o tempo vira moeda e negocia-se o tempo todo. Criar uma fissura em sua malha pode ser um modo de resistir, de escapar. Furálo é provocar um contratempo, um parêntese em aberto; lugar outro por entre os poderes da prisão. Estes outros lugares talvez sejam os campos de resistência e de formação das singularidades na prisão.

Como professor de Ciências da Natureza no CR, aprendo sobre a vida nas prisões, sobre a vida em sociedade, sobre a solidão, sobre o peso do tempo, sobre o conviver com a distância e com a saudade das pessoas queridas, sobre a necessidade da escrita para a vida, com a vida. Ensinam-me como funcionam as regras da casa e quais palavras eu devo usar para que me entendam. Estar dentro da prisão é também compartilhar e circular pelos sentidos que ali estão e são continuamente, dialeticamente, singularmente construídos e desconstruídos.

Em minha trajetória como professor no CR masculino e, também, no CR feminino de Rio Claro, logo percebi que, para quem está privado de sua liberdade, escrever cartas é praticamente o único meio de se comunicar com o exterior, de modo que a escrita atravessa diversos mundos da vida: o amor e a saudade da família, dos amigos, da esposa, dos filhos e filhas; o perdão da sociedade; a solidão fria das grades; o isolamento e esquecimento; a paixão correspondida; as leituras da bíblia e tantos outros.

\footnotetext{
${ }^{4}$ SPIELBERG, S. Amistad. E.U.A, 155 min, 1997.
} 
Durante uma aula de ciências no CR feminino, as educandas que estavam na escola começaram a ficar inquietas: eram as cartas que estavam disponíveis para retirada. Pegar as correspondências e lê-las fez parte daquela aula. Em outro encontro, enquanto passava um poema na lousa, todas as educandas sacaram seus lápis, abriram seus cadernos e começaram a dizer que iriam copiar e mandar para o irmão, para o namorado, para o marido, para a família, para a amiga ou mesmo só para ter no caderno. Sem pedir para que copiassem, escreviam; ainda mais, escrevia-se para alguém. Alguém que pode ser, talvez seja, ela mesma.

No CR masculino, no intervalo de uma aula para outra, eu geralmente ia para a biblioteca conversar com quem estivesse por lá. Certa vez, em uma dessas conversas, um reeducando me disse que, na prisão, ele aprendera uma coisa: a liberdade da mente. Por isso guardava todas as cartas que já escrevera e trocara em sua passagem pelo cárcere, pois, ali, naquelas linhas, ele era livre. Outro educando disse que, na prisão, descobriu o prazer em escrever e que guardava, em uma caixa, os diversos textos que compunha para ele mesmo ou para os outros.

A escrita de cartas é um fazer habitual de quem vive privado de sua liberdade. Escrever que envolve o narrar e registrar histórias. Narração que, como propõe Larrosa (1994), constitui o que se pode chamar de experiência de si.

A experiência de si, historicamente constituída, é aquilo a respeito do qual o sujeito se oferece seu próprio ser quando se observa, se decifra, se interpreta, se descreve, se julga, se narra, se domina, quando faz determinadas coisas consigo mesmo, etc. E esse ser próprio se produz com relação a certas problematizações e no interior de certas práticas. (LARROSA, 1994, p.8)

Se há a experiência de si na escrita dentro das prisões, pode-se dizer que há uma aproximação do que Foucault (1992) chamou de escrita de si. Esta permite acompanhar os movimentos da alma, dá um olhar possível ao que se viu, dá um sentido possível à passagem pela experiência. Escrever seria, portanto, um modo de ver a si mesmo, de se narrar, de jogar com a própria existência em meio às regras, às leis e, no espaço prisional, com a normatividade exercida pela disciplina. Nas oficinas de escrita no contexto prisional, busca-se pensar, com os reeducandos, a prática de escrever quando se está em privação da liberdade.

\section{A oficina como prática educativa e sua dinâmica na prisão}

No dia 14 de outubro de 2016 deu-se início às oficinas educativas intituladas de Travessias da vida: oficina de invenções do cotidiano. Ao total, foram oito encontros, sendo o último no dia 9 de dezembro de 2016. Elas aconteciam das 14h às 16h das sextas-feiras; este foi o horário disponibilizado pela direção da instituição para o desenvolvimento de atividades culturais, entretanto, esse horário não 
permitiu a participação de todos que tinham interesse e desejavam participar, pois alguns trabalhavam fora da unidade e retornavam próximo das $16 \mathrm{~h}$. Também havia problemas para aqueles que estavam no regime interno, pois alguns trabalhos, como na cozinha, por exemplo, não permitiam a participação integral nos encontros. Portanto, embora a própria unidade reserve este horário para atividades culturais, ele entra em conflito com outras atividades do cotidiano da instituição, restringindo as possibilidades de acesso às práticas educativas, assim como suas ampliações.

Os participantes que estiveram presentes em todos os encontros foram Jonas ${ }^{5}$ e Cidadão ${ }^{6}$. Vez ou outra, também participaram outras pessoas. Houve quem assinou o Termo de Consentimento Livre e Esclarecido (TCLE), mas devido ao choque de horário da oficina com o horário de trabalho, não pôde mais comparecer. Houve também aqueles que chegavam no final do encontro para falar um pouco e ver o que estava acontecendo; não havia restrição do grupo em aceitá-los, então abriu-se o espaço para que chegassem e participassem. Acredito que participaram também aqueles que não estavam na roda, mas estavam sentados ao fundo fazendo seus artesanatos e ouvindo a conversa. Havia nos encontros, um pequeno, mas presente, fluxo populacional, assim como há um fluxo populacional em qualquer prisão.

As oficinas não foram somente para escritas ou alguma outra produção visual, como previsto inicialmente. Jonas e Cidadão, que estiveram presentes em todos os encontros, já eram escritores e desejavam mais do que escrever, desejavam compartilhar seus escritos, as vivências e reflexões acerca do sistema prisional. Diante desses interesses, realizei algumas mudanças em relação ao projeto inicial e, de fato, eles escreveram pouco nos encontros, mas, em vários momentos, ocorreram leituras de seus próprios textos. Também houve momentos de perguntas uns para os outros, fortalecendo os laços de intimidade do grupo. A conversa despretensiosa, com aquilo que cada um trazia consigo naquele dia, marcava o início de quase todas as oficinas, e se alongava por quase todo o tempo, até que alguém me perguntava: "e o que você trouxe pra hoje mesmo?". Mas até lá, o programado estava aquém da extensão atingida pela conversa.

Em cada oficina procurei um estado de atenção e de abertura para o que se passava nos encontros. Era um modo de permitir um lugar para a expressão e, assim, tentar compor ou recompor traços de forças que permitem a vida, assim como dizer das forças que a sufocam. Em duas horas, tentar criar territórios que se estendessem semana adentro pelos corpos dos presentes e por entre as regras tão densas daquelas paredes amarelas. Permitir que os próprios diálogos fossem uma escrita pelo ar e formassem corpos múltiplos. Corpo coletivo que se formava do encontro e, às vezes, fazia sumir a prisão e possibilitar uma

\footnotetext{
${ }^{5}$ Em consonância com as exigências do comitê de ética da Secretaria de Administração Penitenciária (SAP), este nome é fictício e foi escolhido pelo próprio educando.

${ }^{6}$ Nome fictício escolhido por mim a partir de seu texto de apresentação.
} 
sensação de expansão. Mas a prisão aparece de novo: barulhos de grades, as conversas que cruzam, o horário que chega e, durante a semana, a pesada rotina que sufoca. Sexta-feira encontrávamo-nos novamente para conversar e aliviar tensões, experimentar a sensação de expansão e de não se perceber na prisão. Expansão e contração, como um movimento de respiração: o corpo vive. Fazeres do cartógrafo, daquele que se propõe a explorar as perspectivas metodológicas da cartografia em uma pesquisa no campo da educação (ROLNIK, 2007).

As oficinas foram, antes de qualquer coisa, um momento para se respirar por entre as pressões da vida aprisionada. Esse processo de combustão se dava pelo diálogo, pela troca de vivências e na confiança em poder falar o que se pensa e ser escutado. A fala não se dirigia para alguém da família e nem para outra pessoa presa; falava-se do que se vivia ali para alguém que era de fora desse contexto. Criava-se, portanto, um espaço educativo com base dialógica, o qual costuma ser ausente nos espaços prisionais. Este diálogo compunha-se principalmente por palavras e, com elas, a intersubjetivação, o enfrentamento e a promoção das consciências: percepções críticas de nosso estar no mundo, problematizações de uma realidade em processo: tessitura de um lugar onde também se experimenta, questiona e se formam modos de se fazer humano e existir (FREIRE, 2005).

A oficina, em sua dinâmica dialógica, rompeu o silêncio e falou-se do que não se fala na prisão: de seus próprios mecanismos marginalizadores em contraposição ao seu discurso reeducador, reformador e ressocializador. Momentos críticos irromperam e, na reelaboração do mundo, a percepção de assujeitados pelas técnicas penais, tornados objetos de um grande sistema. Para Jonas e Cidadão, nada disso é o fim da linha; é na própria linha que se encontra outros modos de resistir e enfrentar esses poderes. Jonas e Cidadão lutam e resistem nesse espaço: a escrita.

\section{As várias margens de um rio}

Nas prisões, onde o sujeito deve ser disciplinado, controlado e reeducado para ser ressocializado, a educação disciplinar é uma das forças que irá produzi-lo, na qual se exclui os indivíduos da esfera das participações, decisões e autonomia. Assim, quando se olha para a escrita como um fazer que ativa a existência, que coloca em movimento as forças capazes de enfrentar o real (FOUCAULT, 1992), a pergunta que atravessa é: o que move e o que pode a escrita dentro da prisão?

Desbordando as estreitezas das situações vividas no cotidiano prisional, pode-se dizer que Jonas e Cidadão encontraram, no movimento da escrita, o contato com a força movente da vida (GRAU, 2016). Presentificar-se com o mundo, com as coisas, com as pessoas e consigo mesmo. Escrita grito-chorodesabafo-instantânea que rompe o tempo gradeadamente linear da prisão, desmonta a palidez do isolamento e o pulso, pulsa. Nos dizeres sobre a experiência de se escrever na prisão, ela aparece como a 
válvula de escape da pressão, lugar de relação consigo e com os outros, de enfrentamento do sistema e de invenção de si.

Em uma das conversas, quando questionei sobre o motivo que os levava a escrever os textos que me apresentavam, Cidadão comentou: "Sempre tive vontade de gritar para que os outros ouvissem o que eu passo aqui. É na hora que a gente acha um tempo vago... nesse tempo aí, pra cabeça soltar aquilo que vai acumulando, a hora que sai, sai uma pancada (a escrita). Pelo menos no meu caso, eu achei uma válvula de escape. Até mesmo as conversas que a gente tá tendo aqui, esses encontros, pra mim é uma válvula de escape”. Jonas, por sua vez, escreve para transmitir suas aprendizagens com a vida aprisionada: "Mais é, o meu objetivo é de aconselhar. Eu entrei nessa pesquisa com você, eu já tinha vontade de escrever essas coisas pra eu aconselhar. Porque nele (referindo-se ao seu caderno) sempre tem alguns poemas, algumas coisas que dá conselho".

Muitas das discussões tinham, como foco, o sistema prisional e a imagem do detento para a sociedade, pois são assuntos pertinentes às suas vidas. Para eles, a prisão está falida e não recupera ninguém, e, pelo contrário, afunda ainda mais as pessoas na marginalidade. Essa constatação é motivo de revolta por parte de Cidadão: "O que eu fico revoltado é de saber que eu tô sendo vítima de um sistema falido, danificado...". Nesse sentimento de revolta, a escrita aparece como a válvula de escape da pressão e, também, como um meio de romper com o silêncio inoperante e tornar-se ação política. Cidadão explica: “[...] É isso que revolta a gente, ver um noticiário desse e a gente se encontrando aqui fala: 'essa cadeia é só pra pobre'. É isso que, não só eu, mas todos aí, a ideia é uma só: 'Por que a lei não vale pra mim e vale pra eles (os políticos)?'. Aí, olha só, a coisa vem assim... A gente tava numa aula de português, era sobre como fazer uma carta de reclamação quando você está insatisfeito com um produto, uma mercadoria, um serviço prestado. Pô, então vou reclamar pro Temer porque eu não estou gostando do serviço prestado que ele tá fazendo".

Nesse contexto, a carta é o meio de comunicação mais presente na prisão. Cidadão e Jonas comentaram que escrevem cartas para os familiares e amigos dos companheiros de pena. Sobre isso, Jonas comentou: "Eu também escrevo muita carta pra família dos outros, gente que eu nunca vi, nem nunca vou ver. Eu escrevo carta como se fosse pra minha mulher, minha mãe, meu pai, meu irmão, meu filho. Eles mandam eu me colocar no lugar deles e escrever. Aí eu ponho o meu sentimento pra eles. Aí, as palavras necessárias pra falar pra eles, eu começo a escrever e vem na mente, Deus vai me dando no coração e eu vou colocando. É legal você poder ajudar as pessoas com a escrita, é bom”. Nessa escrita de um que capta as "vozes" de uma multidão, há um processo de reflexão e reinvenção de si mesmo. Para Cidadão, é isso que acontece ao escrever para os outros na prisão: "Aí que volta lá na sua auto-reflexão, no seu encontro de si mesmo. Eu falo por mim, eu me encontrei e, aí, coisa que eu não fazia lá fora, tipo 
assim, eu não sabia expressar meus sentimentos, meus pensamentos, eu era como eles também (os outros presos que não escrevem), só que eu me busquei, me reinventei”.

Desse encontro consigo, que desagua num processo de escrita, o refazer-se, se dá na própria prática do escrever: lugar das descobertas, invenções e transformações de si. Esse descobrir-se não está na ordem de um encontrar com sua verdadeira essência; aproxima-se de uma não rigidez da individualidade e do tornar-se estrangeiro de si para ouvir a multidão que compõe a existência. Jonas diz sobre o sofrimento da vida em isolamento; Cidadão diz que "O sofrimento conjugado com ambientes de solidão, você encontra seu eu que tava oculto. Você conhece o outro você que tava adormecido. [...] Na verdade nós somos vários eus”.

Com o intuito de conhecer o(s) outro(s), de conhecer nossos vários eus, em uma das oficinas, a proposta era desencadear discussões a partir de um objeto significativo que cada participante tinha consigo no CR. Cada um contava a história do objeto que levara e, assim, constroem-se, em conjunto, reflexões acerca de nossas relações com o mundo. Antes de apresentá-los, conversamos a respeito da prisão e da vida fora dela; reconstruímos um problema imenso, o qual nos fez pequenos demais diante das macroestruturas da sociedade. A ideia de um caminho sem saída se aproximava e, então, fiz a seguinte pergunta: "Diante desses problemas todos da sociedade, da prisão, da justiça, o que eu faço comigo mesmo? Desisto ou luto? Como?”. A conversa reviveu e adquiriu novos rumos; os objetos levantaram-se como resposta de combate. Jonas logo puxou as primeiras palavras: “Eu não desisto. Depois que eu fui preso, eu penso assim, que a única coisa que eu tenho que fazer é conscientizar os outros, falar, mesmo que as pessoas não me ouçam. [...]. Por mais sofrido que seja, difícil, mas tem que falar”. Ele levou seu caderno, no qual falava tudo o que sentia e aprendia em seus dias na prisão. Caderno amigo, companheiro das horas de solidão e tristeza, mas também das alegrias.

Cidadão levou seu objeto de luta que, de acordo com ele, liberta-o, é seu combustível de vida: a caneta. "Posso conquistar o mundo se eu quiser. Só utilizar a cabeça e a criatividade e ela faz tudo. Depende de mim”, disse Cidadão. Eu quis saber quando ele descobriu a caneta como esse objeto libertador; ele respondeu: “A prisão me trouxe uma coisa boa. Lá fora, na rua, eu quase não escrevia. Eu tinha o pensamento, mas quase não praticava. E aqui eu tenho tempo pra isso”.

Escrita como prática do pensamento que se processa no momento mesmo de estar vivenciando o encarceramento. Não é de fora sobre o dentro e nem depois, como lembrança. Isso se dá, pode-se dizer, no presente. Quando questionado se há diferença entre escrever dentro e escrever fora da prisão, Jonas, que já possuía o hábito de escrita, esclareceu: “Tem, e grande! Não é tão pequena. Quando você escreve igual nós escreve, aqui, no momento em que nós tá passando a saudade, a angústia de estar longe de 
nossos familiares, a ansiedade de ser resolvido logo esse processo, então, quando nós começa a escrever, o sentimento nosso aflui”.

A despedida, no final de cada encontro, era um tanto demorada e o andar, rumo ao corredor, vagaroso. Adentrá-lo era retornar ao cotidiano prisional. Corredor estreito onde ecoam os sons de televisores, risadas e chinelos. Ecoam também as memórias, vozes, e escolhas por entre as ondas do pensamento. No CR não se grita e nem se exalta, não se conta tudo para o outro, nem para a família. Então quem segura a onda? Para Jonas e Cidadão - e possivelmente para tantos outros em uma população de aproximadamente 220 - é entre as margens das folhas de seus cadernos por onde navegam seus ecos, ondas e devires.

Escrita que atravessa a vida e aflui os sentimentos. Vida atravessada pelas grades da prisão. Vida e escrita que, ao entrelaçar as linhas da existência, faz refletir a filigrana da liberdade.

\section{Considerações Finais}

Enquanto uma instituição total, que “[...] pode ser definida como um local de residência e trabalho onde um grande número de indivíduos com situação semelhante, separados da sociedade mais ampla por considerável período de tempo, levam uma vida fechada e formalmente administrada" (GOFFMAN, 1974, p.11), a prisão pretende controlar a vida de quem ali vive. Diante dessa tentativa de controle, os prisioneiros resistem ao criarem as fissuras e escapar, de algum modo, ao confinamento a que estão subjulgados. Criam meios de reaproveitar e dividir os alimentos, trocar mercadorias e comunicar-se. Essas invenções me sugerem uma aproximação com o que Boechat e Kastrup (2009) entendem do que Foucault chamou de processos de subjetivação:

Foucault aponta a subjetivação como um eixo integrante da relação entre o poder, como vetores de força, e o saber, como dimensão da verdade e do conhecimento. As práticas de subjetivação e o cuidado de si derivam de códigos morais e de condutas normativas, conferindo a eles uma dimensão moduladora e individualizante. [...] A maneira como um sujeito obedece ou resiste a regras, como respeita ou negligencia os valores e seus modos de sujeição às normas constituem margens de variação única. No universo prisional, as práticas de si variam a partir das nuances das leis e normas. (FOUCAULT, 1984 apud BOECHAT; KASTRUP, 2009, p.26)

Olhar para como convivem as pessoas presas em meio às suas práticas cotidianas, abre janelas para se pensar as relações dos sujeitos com os poderes e os saberes exercidos e produzidos pela instituição. Assim, é nas invenções de modos de existir dentro das prisões que se torna possível encontrar pegadas de uma caminhada que atravessa o poder disciplinar e que, às vezes, dele escapa.

Com Foucault (1992, p.133), pode-se pensar a escrita como um modo de produzir a si por si mesmo, um "exercício do pensamento sobre si mesmo que reativa o que ele sabe, se faz presente em 
princípio, uma regra ou um exemplo, reflete sobre eles, os assimila, e se prepara para enfrentar o real”. É um fazer consigo, de voltar a si e atualizar pensamentos e ações no mundo: função etopoiética do escrever, que objetiva transformar o modo de ser dos indivíduos (BRAGA, 2014). A escrita se apresenta como movimentos que permitem um olhar a si em (trans)formação, como explica Braga (2014, p.51):

A escrita [...] também é um exercício formativo em pleno desenvolver-se. Envolve a possibilidade estilística de um si mesmo na medida em que pretende interpretações de uma ação própria. Gera movimentos de distanciamentos e aproximação com aquilo que se é ou está em vias de se tornar.

Enquanto gesto transformativo de si não quer dizer que a escrita esteja relacionada a um problema pessoal, mas, sim, que ela se relaciona com a vida (DELEUZE, 1988/89). Para Deleuze (1988/89), escreve-se porque algo da vida passa em nós e, no escrever, tornamo-nos alguma coisa que não escritor. Escrever é devir (DELEUZE, 1988/89; 2011).

Se é pela escrita que nos tornamos outros, pode-se dizer que é por meio dela que tomamos uma distância de nós mesmos. Distanciar-se de si está mais próximo de um perder de si mesmo do que de um encontro consigo mesmo. Portanto, o escrever trata-se de uma prática de estranhar-se, tornar-se estrangeiro de si e colocar, na identidade, pontos de tensão (VIGNALE, 2016).

A mesma autora (2016) afirma que nesse processo de escrita como estranhamento de si não se escreve de onde queremos ou sobre o que escolhemos, menos ainda como uma prática do livre pensar e da boa vontade. Escrevemos onde algo dói, onde algo grita ou goza, todo pensamento e escrita tem a ver com questões de intensidades e ressonâncias. Escreve-se para gerar um abismo consigo mesmo; espaço para criar-se. Escrever, portanto, para se tornar outros.

Nesse sentido, a prática da escrita é um descolar de si e não uma reafirmação do que se é. Esse movimento é o que permite desatar os discursos de verdade sobre si mesmo e começar a desenhar outras formas de si. "Escribir para escucharnos a nosostros mismos y narrarnos" (VIGNALE, 2016, p.74). Nessa relação com a palavra, com os sentidos de um mim-outro, torna-se criador de verdades para si mesmo, um modo de produzir-se em resistência aos poderes de assujeitamento.

Pensando com Deleuze (2013), o escrever como um modo de produzir-se a si frente às forças de assujeitamento é, portanto, um modo de relação das forças consigo; trata-se da dobra da força que, segundo o autor (2013, p.120):

Segundo a maneira de dobrar a linha de força, trata-se da constituição de modos de existência, ou da invenção de possibilidades de vida [...]. Trata-se de inventar modos de existência, segundo regras facultativas, capazes de resistir ao poder bem como se furtar ao saber, mesmo se o saber tenta penetrá-los e o poder tenta apropriar-se deles. Mas os modos de existência ou possibilidades de vida não cessam de se recriar, e surgem novos. 
Escrita enquanto devir, criação e resistência; experimentações de singularidades em movimento que resistem e escapam aos territórios do poder e do saber, ao mesmo tempo em que inventam outros lugares de existência. Escrita que permite a criação de um espaço-tempo outro por entre as regras e normas da prisão. Espaço-tempo outro que permite, por vezes, uma fuga e, quase sempre, a resistência.

\section{Referências}

BARATTA, Alessandro. Enfoque crítico del sistema penal. In: ELBERT, Carlos Alberto (dir.); BELLOQUI, Laura. (coord.). Criminologia y sistema penal: compilación in memoriam; Montevideo-Buenos Aires: Editora B de F, 2004a. p.89-112.

BARATTA, Alessandro. Resocialización o controle social. Por um concepto crítico de "reintegración social" del condenado. In: ELBERT, Carlos Alberto (dir.); BELLOQUI, Laura. (coord.). Criminologia y sistema penal: compilación in memoriam; Montevideo-Buenos Aires: Editora B de F, 2004b. p.376-393.

BAUMAN, Zygmunt. Globalização: as consequências humanas. Rio de Janeiro: Jorge Zahar, 1999.

BOECHAT, Myrna; KASTRUP, Virgínia. A experiência com a literatura em uma instituição prisional. Revista Psicologia em revista, Belo Horizonte, PUC Minas, v.15, n.3, p.22-40, ago., 2009.

BRAGA, Jonathan Taveira. Formação-Arte-Escrita: Contribuições estéticas para a noção de experiência. 2014. 127f. Dissertação (Mestrado em Educação) - Programa de Pós-Graduação em Educação da Universidade Estadual Paulista, UNESP, Rio Claro, 2014.

BUENO, Luciano. Humanizando a Política Carcerária: Cidadania no Cárcere. 20 experiências em gestão pública e cidadania, São Paulo, p.47-56, 2005. Disponível em: $<$ http://bibliotecadigital.fgv.br/dspace/bitstream/handle/10438/15747/relatorio_completo_2005.pdf?sequence=1 >. Acesso em: 07 jun. 2017.

CAMPOS, Aline. Educação, escola e prisão: O "espaço de voz" de educandos do centro de ressocialização de Rio Claro/SP. 2015. 275f. Dissertação (Mestrado em Educação) - Programa de Pós-Graduação em Educação, Centro de Educação e Ciências Humanas da Universidade Federal de São Carlos, UFScar, São Carlos, 2015.

COSTA, Gizelda Morato. As Organizações Não Governamentais no Sistema Penitenciário do Estado de São Paulo: protagonistas constitutivas de novos modelos prisionais ou reprodutoras dos modelos tradicionais? 2006. 112f. Dissertação (Mestrado em Serviço Social) - Pontifícia Universidade Católica de São Paulo, São Paulo, 2006.

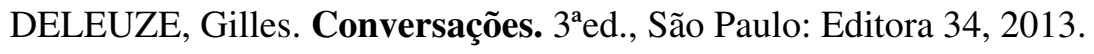

DELEUZE, Gilles. O abecedário de Gilles Deleuze. 1988/89. Entrevista disponível em: $<$ http://escolanomade.org/wp-content/downloads/deleuze-o-abecedario.pdf>. Acesso em: 07 jun. 2017

DOSTOIÉVSKI, Fiódor. Recordação da casa dos mortos. 4ª ed., Rio de Janeiro: José Olympio Editora, 1953.

FAUSTINO, Eliana Ribeiro. Centro de Ressocialização: a humanização da pena como caminho para a reintegração social. 2008. 150f. Dissertação (Mestrado em Serviço Social e Política Social), Universidade Estadual de Londrina, Paraná, 2008.

FAUSTINO, Eliana Ribeiro; PIRES, Sandra de Abreu. Os centros de ressocialização e o processo de trabalho do assistente social. Revista Emancipação, Ponta Grossa, Universidade Estadual de Ponta Grossa, v.7, Ed. UEPG, p. 47-61, 2007.

FREIRE, Paulo. Pedagogia do oprimido. Rio de Janeiro: Paz e Terra, 2005. 
FOUCAULT, Michel. A escrita de si. In: O que é um autor? Lisboa: Passagens, p. 129-160, 1992.

FOUCAULT, Michel. Microfísica do poder. 27ª ed, São Paulo: Graal, 2013.

FOUCAULT, Michel. Vigiar e punir: nascimento da prisão. 25ª Ed. Petrópolis: Vozes, 2002.

GALEANO, Eduardo. De pernas pro ar: a escola do mundo ao avesso. Vol. 820. Porto Alegre, RS: L\&PM Editores, 2013.

GRAU, Olga. La duración en el espacio educativo. In: KOHAN, Walter Omar; LOPES, Sammy; MARTINS, Fabiana (Orgs). O ato de educar em uma língua ainda por ser escrita. Rio de Janeiro: Nefi, 2016. p.431-438.

GOFFMAN, Erving. Manicômio, Prisões e Conventos. São Paulo: Perspectiva, 1974.

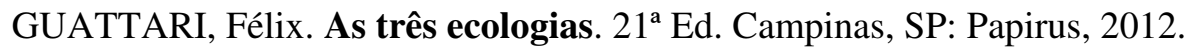

IRELAND, Timothy Denis. Educação em prisões no Brasil: direito, contradições e desafios. In: (org.)

Educação em Prisões. Revista Em aberto, Brasília, Inep, v. 24, n. 86, p. 19-35, nov. 2011.

KASTRUP, Virgínia. O funcionamento da atenção no trabalho do cartógrafo. Psicologia e Sociedade, Porto Alegre, vol. 19, n.1, p.15-22, 2007.

LARROSA, Jorge. Notas sobre experiência e o saber de experiência. Revista Brasileira de Educação, $\mathrm{n}^{\circ}$ 19, $\mathrm{p}$. 20-28, jan/abr 2002.

LARROSA, Jorge. Tecnologias do eu e educação. In: SILVA, Tomaz Tadeu da. O sujeito da educação: estudos foucaultianos. Petrópolis: Vozes, 1994. p. 35-86.

MONTEIRO, Felipe Mattos; CARDOSO, Gabriela Ribeiro. A seletividade do sistema prisional brasileiro e o perfil da população carcerária: um debate oportuno. Revista Civitas, Porto Alegre, PUC - Rio Grande do Sul, v.13, n.1, p.93-117, jan. 2013.

OLIVEIRA, Thiago Ranniery Moreira de; PARAÍSO, Marlucy Alves. Mapas, danças, desenhos: a cartografia como método de pesquisa em educação. Revista Pro-posições, Campinas, Unicamp, v.23, n.3, p.159-178, 2012.

RAITZ, Tania Regina; CHIARELOTTO, Arivane Augusta. Sociologia da educação: uma leitura dos novos objetos de pesquisa. Revista Contrapontos, Campinas, Unicamp, v. 5, n.1, p.95-107, 2005.

ROLNIK, Suely. Cartografia sentimental: transformações contemporâneas do desejo. Porto Alegre: Sulina/Ed. UFRGS, $2^{\mathrm{a}}$ ed., 2007.

TEJERINA, Diego Gabriel. Estudiar en la cárcel: lógicas y sentidos de la vida universitaria en el CUSAM. 2016. 83f. Tesina de Licenciado em Sociología - Instituto de Altos Estudios Sociales (IDAES) da Universidad Nacional de San Martín - UNSAM, San Martín, 2016.

VEDOVELLO, Camila de Lima. Novas formas de encarceramento? Os jovens e o centro de ressocialização. 2008. 182f. Dissertação (Mestrado em Ciências Sociais) - Programa de Pós-Graduação em Ciências Sociais da Faculdade de Filosofia e Ciências da Universidade Estadual Paulista - UNESP, Marília, 2008.

VIGNALE, Silvana. Prefacio para una política de la escritura. In: CALLAI, Cristiana; RIBETTO, Anelice (Orgs). Uma escrita acadêmica outra: ensaios, experiências e invenções. Rio de Janeiro: Lamparina, 2016. p.68-74

WACQUANT, Loic. As prisões da miséria. $2^{\mathrm{a}}$ ed, Rio de Janeiro: Zahar, 2011. 


\section{Revisores}

Língua Portuguesa

Língua Inglesa
Nome: Thaís Arruda Ferreira

E-mail: thais.revisao@gmail.com

Nome: Mariana Ferrari Waligora

E-mail: marifwal@gmail.com
Língua Espanhola

Nome: Nora Migliori

E-mail: hh.nora@gmail.com 